\title{
A Rare Cause of Gastrointestinal Bleeding: Crimean-Congo Haemorrhagic Fever Disease
}

\author{
Elif Börekçi ${ }^{1}$, Mehmet Çelikbilek², Tuğba Özdemir ${ }^{1}$, Çiğdem Kader ${ }^{3}$, Hasan Börekçi \\ ${ }^{1}$ Department of Internal Medicine, Bozok University, School of Medicine, Yozgat, Turkey \\ ${ }^{2}$ Department of Gastroenterology, Bozok University, School of Medicine, Yozgat, Turkey \\ ${ }^{3}$ Department of Infectious Diseases and Clinical Microbiology, Bozok University, School of Medicine, Yozgat, Turkey \\ ${ }^{4}$ Department of General Surgery, Bozok University, School of Medicine, Yozgat, Turkey
}

\section{Dear Editor,}

Crimean-Congo Haemorrhagic Fever (CCHF) disease is a viral haemorrhagic fever syndrome present in Turkey since 2002 [1]. CCHF is transmitted by ticks and can be fatal. Thrombocytopenia and coagulopathy can develop and, because of severe bleeding in the gastrointestinal tract, the prognosis is poor. After 3-7 days of incubation, fever, headache, fatigue, generalised muscle pain, nausea, vomiting, and skin and mucosal haemorrhages can occur [2]. J Microbiol Infect Dis 2016;6(1): 38-39

Key words: CCHF, endoscopy, gastrointestinal bleeding

An 83-year-old male patient was admitted to our emergency department because of weakness, fatigue, and generalised muscle pain 4 days in duration. He was a retired worker living close to the pine area in Yozgat and he was not deal with animals. Upon physical examination, he was hypotensive and tachycardic, and ecchymotic areas of haemorrhage were widespread in both the lower and upper extremities and the body. His body temperature was $37.6^{\circ} \mathrm{C}$. Laboratory findings were: leukocytes $2,710 /$ $\mathrm{mm}^{3}$, haemoglobin: $10.9 \mathrm{~g} / \mathrm{dL}$, platelets: $23,000 /$ $\mathrm{mm}^{3}$, creatine kinase $156 \mathrm{mg} / \mathrm{dL}$, lactate dehydrogenase $569 \mathrm{lU} / \mathrm{L}$, C-reactive protein $54 \mathrm{mg} / \mathrm{L}$, activated partial thromboplastin time $44.5 \mathrm{~s}$, prothrombin time $10.4 \mathrm{~s}$, and international normalised ratio= 0.8. Melena was present. Upper gastrointestinal endoscopy revealed superficial erosions with oozing haemorrhages in the oesophagus, and multiple oozing bleeding ulcers up to 7-8 $\mathrm{mm}$ in diameter with adherent fresh blood clots in the stomach and duodenum (Figure 1). There was no history of contact with ticks, but living in the endemic area, and the current laboratory and clinical findings brought to mind of the CCHF disease in the differential diagnosis. Our suspicion of CCHF was confirmed by polymerase chain reaction. Upon supportive care, the patient improved in about one week.

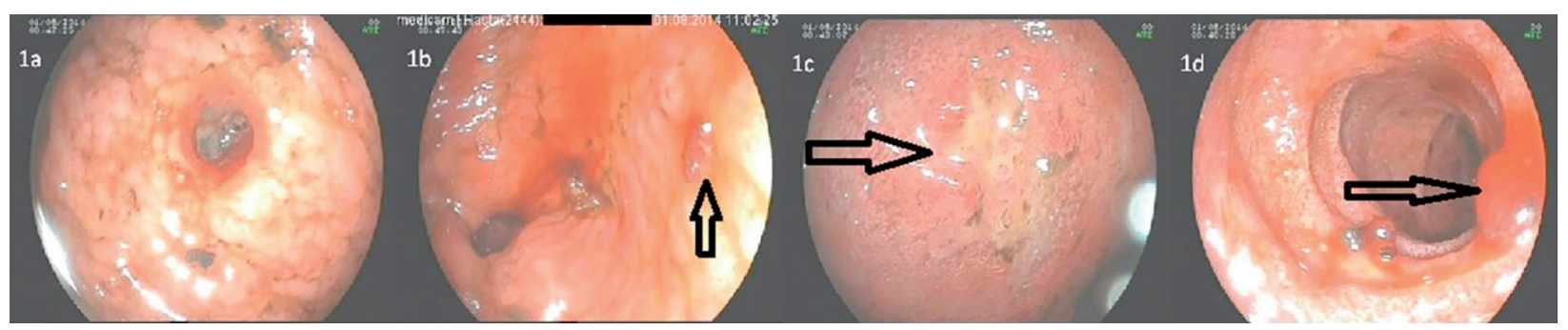

Figure 1: Upper gastrointestinal endoscopic images showing mucosal haemorrhages caused by CCHF. 1a: the corpus of the stomach, $1 \mathrm{~b}$ : the antrum of the stomach, $1 \mathrm{c}$ : the duodenal bulb, $1 \mathrm{~d}$ : the second portion of the duodenum.

To protect healthcare workers from the risk of $\mathrm{CCHF}$ infection, any marked combination of clinical features-such as thrombocytopenia, fever, myalgia, and extensive gastrointestinal mucosal bleedingsshould engender a suspicion of $\mathrm{CCHF}$ in clinicians, especially in endemic areas. 
Declaration of Conflicting Interests: No conflict of interest of any author exists.

Financial Disclosure: The authors declared no financial support.

\section{REFERENCES}

1. Gönen I, Ermiş F. Crimean-Congo hemorrhagic fever presenting with gastrointestinal manifestations: two cases. Turk J Gastroenterol. 2014 ;25:120-121.

2. Ergönül O. Crimean-Congo haemorrhagic fever. Lancet Infect Dis. 2006; 6:203-214. 